\title{
Cigarette smoke induces CXCL8 production by human neutrophils via activation of TLR9 receptor
}

\author{
E. Mortaz*,,, , I.M. Adcock*, K. Ito ${ }^{+}$, A.D. Kraneveld*, F.P. Nijkamp* and G. Folkerts*
}

ABSTRACT: Chronic obstructive pulmonary disease (COPD) is a major health problem and cigarette smoke is the main risk factor for the development of COPD. The characteristic changes in airway morphology, inflammatory cell infiltration and mediator expression in COPD may result from direct effects of cigarette smoke on airway cells. Toll-like receptors (TLRs) are key elements in pathogen recognition by the host immune system. Although TLRs have been intensely studied in innate immunity and infection, their critical role in noninfectious challenges has only recently emerged.

Here we investigate whether cigarette smoke induces TLR9 signalling in human neutrophils. Human neutrophils were isolated from buffy coat and exposed to cigarette smoke extract. The production of $\mathrm{CXC}$ chemokine ligand (CXCL) 8 was measured as a functional readout and the role of TLR9 signalling was investigated. Cigarette smoke extract induced CXCL8 release via TLR9 activation in neutrophils, which was confirmed in TLR9 stably transfected human embryonic kidney 293 cells. Moreover, cigarette smoke extract upregulated the expression of TLR9 and the upregulated expression was suppressed by $\mathrm{N}$-acetylcysteine.

TLR9 mediates cigarette smoke-induced release of CXCL8 and this may contribute to the accumulation of neutrophils and inflammation within the airways of smokers.

\section{KEYWORDS: Cigarette smoke, neutrophils, Toll-like receptors}

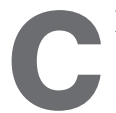
hronic obstructive pulmonary disease (COPD) is recognised as a major cause of death worldwide and poses an increasing global healthcare problem [1]. As previously stated [2], the definition of COPD recognises the "abnormal", exaggerated or amplified inflammatory response in the lung and systemically to cigarette smoking. The pattern of inflammation involves recruitment of lymphocytes, macrophages and neutrophils, as well as activation and damage to structural cells following the release of inflammatory chemokines and cytokines [2-5]. In the Western world, the major driver of disease is cigarette smoke which is a complex mixture of organic chemicals, heavy metals and reactive oxygen species (ROS) [6-11]. Importantly, SOPORI [12] highlighted that chronic inhalation of cigarette smoke can modulate both innate and adaptive immune responses. Moreover, it has been speculated that many of the health consequences of chronic inhalation of cigarette smoke might be due to its adverse effects on the immune system [13].

It is likely that smokers develop airway inflammation through oxidative stress. Cigarette smoke activates macrophages and neutrophils to release proinflammatory mediators, chemokines and elastolytic enzymes [14]. CXC chemokine ligand (CXCL) 8 is an important chemokine produced by macrophages, neutrophils and epithelial cells and induces the recruitment of neutrophils to the airways $[15,16]$. As a part of the innate immune response, pattern recognition receptors mediate the interaction between conserved patterns on micro-organisms and the host. Toll like receptors (TLRs) are pathogen-associated molecular-pattern receptors for diverse microbially derived molecules expressed predominantly on innate immune cells [17]. To date, 11 TLR family members have been identified in the human genome [18, 19]. Bacterial DNA containing unmethylated CpG motifs act as important regulators of human neutrophil functions via TLR9. For example, stimulation of the TLR9 pathway via CpG oligonucleotides (ODN), induces CXCL8 production by neutrophils via the generation of peroxynitrite $\left(\mathrm{ONOO}^{-}\right)$[20].

Recently, we and others have demonstrated that cigarette smoke extract (CSE) activates TLR4 signalling [17, 21, 22]. Furthermore, TLR4 seems to play a critical role in the development of lung

\section{AFFILIATIONS}

*Division of Pharmacology and Pathophysiology, Utrecht Institute for Pharmaceutical Sciences, Faculty of Sciences, Utrecht University, Utrecht, The Netherlands.

"Dept of Clinical Biochemistry, Faculty of Medical Sciences, Tarbiat Modares University, Tehran,

'Dept of Basic Science, Section of Biochemistry, Faculty of Veterinary Medicine, Urmia University, Urmia, Iran.

${ }^{+}$Airways Disease Section, National Heart and Lung Institute, Imperial College London, London, UK.

CORRESPONDENCE

E. Mortaz

Division of Pharmacology and

Pathophysiology

Utrecht Institute for Pharmaceutical

Sciences

Faculty of Sciences

Utrecht University

P.0. BOX 80082

3508 TB Utrecht

The Netherlands

E-mail: emortaz@gmail.com

Received:

April 142009

Accepted after revision:

April 092010

First published online:

April 222010 
emphysema [23]. In the current study, we investigated whether CSE could also regulate TLR9 signalling in neutrophils. Thus, the present study was conducted to clarify TLR9 activation and expression in human primary neutrophils in response to CSE using the production of CXCL8 as a functional readout for TLR9 activation. Moreover, the involvement of ROS and a major signal transduction pathway (nuclear factor (NF)- $\mathrm{kB}$ ) were investigated by the use of pharmacological inhibitors. The activation of NF- $\kappa B$ by CSE via TLR9 activation was also determined using genetic methods by overexpression of TLR9 in receptor-deficient cells and the subsequent analysis of NF- $\mathrm{KB}$ reporter gene activity.

\section{MATERIALS AND METHODS \\ Reagents}

Lipopolysaccharides (Escherichia coli 055.B5), N-acetylcysteine (NAC), curcumin, chloroquine, propidium iodide and $N^{\mathrm{G}}$ nitro-L-arginine methyl ester (L-NAME) were purchased from Sigma (Sigma-Aldrich, Zwijndrecht, The Netherlands). Roswell Park Memorial Institute (RPMI) 1640, Tyrode's buffer, fetal calf serum (FCS), nonessential amino acids, 2' ,7'-dichlorfluoresceindiacetate (DCFH-DA) (D399) and diaminofluorescein diacetate (DAF) were purchased from GibCo BRL Life Technologies (GIBCO-BRL-Invitrogen Corporation, Carlsbad, CA, USA). Rabbit polyclonal antibody against TLR9 was obtained from Santa Cruz Biotechnology (Tebu-bio, Heerhugowaard, The Netherlands). The precision protein standards and polyvinylidene fluoride (PVDF) membrane were purchased from Bio-Rad (Bio-Rad Laboratories, Veenendaal, The Netherlands). Horseradish peroxidase (HRP)-conjugated rabbit-anti mouse immunoglobulin (Ig)G and goat anti-rabbit IgG were purchased from Dako Diagnostics (Dako B.V. Heverlee, Belgium). CpG ODN 2395 stimulatory oligonuleotide, negative blocking control inhibitory ODN without the CpG motif (inhibitory ODN with sequence 5'-tttagggttagggttagggttaggg-3, ODN control (ODN 2395 control) with sequence 5'-tgctgcttttggggggccccc-3', Blasticidin $\mathrm{S}$ and QUANTI-Blue ${ }^{\mathrm{TM}}$ reagent were purchased from Invivogen (Cayla-InvivoGen Europe, Toulouse, France). Anti-tumour necrosis factor receptor-associated factor 6 (antiTRAF6) (catalogue number sc-7221) and anti-interleukin (IL) receptor-associated kinase-1 Ab (catalogue number 06-872) antibodies were purchased from Santa Cruz Biotechnology and Upstate (Haarlerbergweg, The Netherlands), respectively. Bicinchoninic acid (BCA) protein assay kit and super-blocking buffer were purchased from Pierce (Perbio Science B.V, EttenLeur, The Netherlands).

Protein A-Sepharose bead slurry and ECL or ECL Plus were purchased from Amersham Biosciences (Buckinghamshire, UK). TRIzol reagent and p-nifty $2 \times \mathrm{NF}-\kappa \mathrm{B}$ secreted embryonic alkaline phosphatase (SEAP) plasmid and Sybergreen Universal PCR Master Mix and SuperScript III reverse transcriptase were purchased from Invitrogen (Carlsbad, CA, USA). TransAM NF- $\kappa$ B p65/NF- $\kappa$ B p50 Transcription Factor Assay Kit (Active Motif, Rixensart, Belgium). Phycoerythrin (PE)-labelled TLR9 and isotype IgG control were purchased from ebioscience (San Diego, CA, USA).

\section{Preparation of CSE}

Cigarette smoke-conditioned medium was produced as previously described [17]. CSE was generated by the burning of commercially available cigarettes without filter, with tar
$12 \mathrm{mg}$, nicotine $0.9 \mathrm{mg}$ and CO $9 \mathrm{mg}$, using the TE-10z smoking machine (Teague Enterprises, Davis, CA, USA), which is programmed to smoke cigarettes according to the Federal Trade Commission protocol (35-mL puff volume drawn for $2 \mathrm{~s}$, once per minute). Briefly, this machine was used to direct main- and side-stream smoke from one cigarette through a 5-mL culture medium (RPMI without phenol red). Hereafter, absorbance was measured spectrophotometrically at $320 \mathrm{~nm}$ and this number was taken as $100 \%$. The $\mathrm{pH}$ of the resultant extract was titrated to $\mathrm{pH} 7.4$ with medium, to different concentrations $(0.75-3 \%)$. A $1.5 \%$ solution was used in the present study following preliminary experiments that indicated that this was non-toxic (viability $\geqslant 96 \%$ ) and demonstrated a good induction of CXCL8 release [24].

\section{Isolation of neutrophils}

Human neutrophils were isolated from healthy volunteers as previously described [25]. Briefly, human neutrophils were obtained from heparinised venous blood buffy coat by FicollHypaque centrifugation, followed by sedimentation in $5 \%$ dextran $/ 0.9 \%$ saline. Neutrophils were separated from erythrocytes by lysis in a solution of $0.15 \mathrm{M} \mathrm{NH}_{4} \mathrm{Cl}, 0.01 \mathrm{M} \mathrm{NaHCO}$ and $0.01 \mathrm{M}$ tetra-EDTA. The recovered neutrophils were resuspended in RPMI 1640 medium supplied with 10\% fetal calf serum and essential amino acids and $10 \mathrm{mM}$ 4-(2-hydroxyethyl)-1piperazineethanesulfonic acid (HEPES), pH 7.2, and washed three times. The purity of neutrophils preparations was $>93-95 \%$, as determined by Wright's staining of cytospin preparations. Cell viability of these cells was $97 \%$, as determined by trypan blue exclusion. Neutrophils were kept on ice until used. For each experiment, $\mathrm{n}$ represents the number of separate individual donors used for each individual study.

\section{Cell lines}

TLR9 stably transfected human embryonic kidney (HEK) 293 cell lines (293XL-hTLR9, catalogue number 293xl-htlr9 for TLR9) and null HEK 293 (293-null, catalogue number 293-null) were purchased from Invivogen. Cells were cultured in Dulbecco's modified Eagle's medium (DMEM) supplied with 10\% FCS and $10 \mathrm{mg} \cdot \mathrm{mL}^{-1}$ of the antibiotic, blasticidin $\mathrm{S}$, each for 3 days.

\section{Cell activation}

Neutrophils $\left(5 \times 10^{6}\right.$ cells $\left.\cdot \mathrm{mL}^{-1}\right)$ were incubated for $20-30 \mathrm{~min}$ with L-NAME (0.1-10 mM) or NAC (0.1-10 mM); chloroquine (1-50 $\mathrm{mg} \cdot \mathrm{mL}^{-1}$ ) (enhances endosomal $\mathrm{pH}$ and thereby blocks lysomal pathways and used here as a blocker of TLRs signalling) [26] or blocking anti-sense ODN (1-10 mM) and then stimulated with CSE $(1.5 \%)$, CpG ODN type A $(3 \mu \mathrm{M})$ or control ODN (5 mM) for $30 \mathrm{~min}$ for western blot analysis. For CXCL8 determination $3 \times 10^{6}$ cells $\cdot \mathrm{mL}^{-1}$ were incubated for $9 \mathrm{~h}$ according to the conditions for Western blot analysis. For determination of intracellular CXCL8 expression, HEK 293 stably transfected TLR9 or null cells were stimulated with CSE or CpGODN for $6 \mathrm{~h}$, and the whole cells extracts were subjected for western blot analysis. For preparation of samples for RT-qPCR, cells were activated for different time points with CSE or CPG ODN as described. The viability of cells before and after each experiment was determined by staining with propidium ionide or 7-ADD labelled with fluorescein isothiocyanate using flow cytometery (fluorescence-activated cell sorting (FACS) analysis). 


\section{Quantification of CXCL8 and cytokine assay}

CXCL8 concentrations in cell supernatants were quantified using ELISA (BD Biosciences Pharmingen, Breda, The Netherlands) according to the manufacturer's instructions. The production of other inflammatory cytokines (tumour necrosis factor (TNF)- $\alpha$, IL-6) was also measured in culture medium using CBA Kits (BD Biosciences Pharmingen) and flow cytometry (FACScalibur; BD Biosciences Pharmingen) according to the manufacturer's instructions.

\section{Measurement of intracellular ROS stress and NO}

Cells $\left(1 \times 10^{6}\right.$ cells $\left.\cdot \mathrm{mL}^{-1}\right)$ were activated with CSE $(1.5 \%)$ or CpG ODN $(3 \mu \mathrm{M})$ for 1 and $5 \mathrm{~h}$. After two washes with cold PBS, cells were pre-incubated with $10 \mu \mathrm{M}$ redox-sensitive dye DCFH-DA (D399) for measurement of ROS and $5 \mu \mathrm{M}$ of DAF for determination of $\mathrm{NO}$ for $20 \mathrm{~min}$ as previously described $[27,28]$. Intracellular levels of ROS and NO were determined by flow cytometry (FACScalibur). The data were plotted and analysed using CellQuest (BD Biosciences Pharmingen) software.

\section{Anti-TLR neutralisation of cytokine production}

Cells were incubated with anti-human TLR2 (clone TL2.1) or mouse IgG2a isotype control $\left(20 \mu \mathrm{g} \cdot \mathrm{mL}^{-1}\right)$, for $30 \mathrm{~min}$ at room temperature or with anti-human TLR4 (clone HTA125) or mouse IgG2a isotype control $\left(20 \mu \mathrm{g} \cdot \mathrm{mL}^{-1}\right.$ ) (all from eBioscience, CA, USA) for $1 \mathrm{~h}$ at $37^{\circ} \mathrm{C}$. Thereafter, cells were stimulated with CSE $(1.5 \%)$ and incubated overnight. Supernatants were collected and stored at $-20^{\circ} \mathrm{C}$ prior to CXCL8 quantification.

\section{Preparation of whole cell extracts}

Neutrophils were plated at a density of $5 \times 10^{6}$ cells $\cdot \mathrm{mL}^{-1}$ in 6-well cell culture plates and stimulated (as described previously) for $30 \mathrm{~min}$. Cells were washed twice with PBS and lysed with lysis buffer containing $20 \mathrm{mM}$ Tris pH 7.5, 1\% Triton X-100, $100 \mathrm{mM}$ $\mathrm{NaCl}, 40 \mathrm{mM} \mathrm{NaF}, 1 \mathrm{mM}$ EDTA with protease inhibitors (MiniTM protease inhibitors; Roche Diagnostics, Burgess Hill, UK). Cells were subsequently lysed on ice for $5 \mathrm{~min}$ and, following centrifugation at 3,500 $\times g$ for $5 \mathrm{~min}$, the supernatants (whole cell extracts) were collected and frozen at $-70^{\circ} \mathrm{C}$.

\section{Preparation of cytoplasmic and nuclear extracts}

After activation, cells were washed twice with PBS and allowed to equilibrate for $5 \mathrm{~min}$ in ice-cold cytoplasmic extraction reagent (Pierce) containing protease inhibitors (MiniTM protease inhibitors, cocktail). Following centrifugation at 3,500 $\times g$ for $5 \mathrm{~min}$, the supernatants (cytoplasmic extracts) were collected and frozen at $-70^{\circ} \mathrm{C}$. The pellets were re-suspended in nuclear extraction buffer (Pierce) containing protease inhibitors. After vigorous mixing and incubating for $10 \mathrm{~min}$ on ice, the solution was centrifuged at $14,000 \times g$ for $5 \mathrm{~min}$, and the supernatant (nuclear extract) was collected and stored at $-70^{\circ} \mathrm{C}$. Protein concentrations were determined by using a BCA protein assay kit.

\section{Immunoprecipitation of endogenous IL-1R-associated kinase-1 and western blotting}

Neutrophils $\left(15 \times 10^{6}\right)$ were stimulated with CSE $(1.5 \%)$, CpG ODN $(3 \mu \mathrm{M})$ for $10 \mathrm{~min}$ or pretreated with inhibitory ODN $(10 \mathrm{mM})$ for $30 \mathrm{~min}$ and then stimulated with CSE $(1.5 \%)$ for $10 \mathrm{~min}$. After incubation for the indicated times, reactions were stopped with $5 \mathrm{~mL}$ of ice-cold saline with $2 \mathrm{mM}$ phenylmethylsulfonylfluoride (PMSF) and rapid centrifugation. Then, the pellets were immediately frozen in dry ice after aspiration of the supernatants. Afterward, the pellets were lysed with $0.5 \mathrm{~mL}$ of ice-cold extraction buffer containing $20 \mathrm{mM}$ HEPES (pH 7.4), $150 \mathrm{mM} \mathrm{NaCl}, 1 \%$ Triton X-100, $40 \mathrm{mM}$ glycerophosphate, $1.5 \mathrm{mM} \mathrm{MgCl}_{2}, 1 \mathrm{mM}$ EGTA, $1 \mathrm{mM}$ EDTA, $2 \mathrm{mM}$ dithiothreitol, $20 \mathrm{mM} \mathrm{NaF}, 2 \mathrm{mM}$ sodium orthovanadate, $5 \mathrm{mM}$ PMSF, $100 \mu \mathrm{g} \cdot \mathrm{mL}^{-1}$ aprotinin, $10 \mu \mathrm{g} \cdot \mathrm{mL}^{-1}$ leupeptin, $10 \mu \mathrm{g} \cdot \mathrm{mL}^{-1}$ pepstatin. Following a $15-\mathrm{min}$ incubation period on ice, samples were briefly vortexed, transferred to microtubes and centrifuged at $13,000 \times g$, for $10 \mathrm{~min}$ at $4^{\circ} \mathrm{C}$. Supernatants were collected and protein concentration was determined using the Micro BCA Protein Assay Reagent kit (Pierce) according to the manufacturer's instructions. Extracts with equal amounts of proteins were used for immunoprecipitation. The cell lysates $(500 \mu \mathrm{g})$ were precleared by mixing with control rabbit IgG Abs (matched isotype) plus protein Asepharose beads for $1 \mathrm{~h}$ at $4^{\circ} \mathrm{C}$. Then, $4 \mu \mathrm{g}$ of rabbit polyclonal IgG specific for IL-1R-associated kinase (IRAK)-1 was added to the precleared lysates and incubated at $4{ }^{\circ} \mathrm{C}$ for $2 \mathrm{~h}$ on a rotator. Then, immune complexes were captured by the addition of $50 \mu \mathrm{l}$ of prewashed protein A-Sepharose bead slurry and by incubation in a rotator for $1 \mathrm{~h}$ at $4^{\circ} \mathrm{C}$. Sepharose beads were washed three times in ice-cold lysis buffer and then mixed 1:1 with $2 \times$ sample buffer and boiled for $5 \mathrm{~min}$. Then, samples were subjected to SDS-PAGE, transferred to PVDF membrane and immunoblotted with rabbit polyclonal Ab anti-TRAF6 and detected with enzymatic chemiluminescence (ECL).

\section{Western blotting}

For western blot analysis, cells were washed once with cold PBS and lysed in ice-cold lysis buffer containing $50 \mathrm{mM}$ Tris ( $\mathrm{pH}$ 8.0), $110 \mathrm{mM} \mathrm{NaCl}, 5 \mathrm{mM}$ EDTA, 1\% Triton $\mathrm{X}-100$ and $100 \mu \mathrm{g} \cdot \mathrm{mL}^{-1}$ PMSF. Protein concentration was determined by BCA protein assay kit and (30-50 mg) protein was subjected were subjected to SDS-PAGE (10\% (weight/volume)) gel. The separated proteins were electro-blotted on PVDF membranes. Membranes were then washed once with Tris-HCI pH 7.4, containing $159 \mathrm{mM} \mathrm{NaCl}$ and 1\% Tween 20 (TBS-T), and then blocked in super-blocking buffer for $1 \mathrm{~h}$. After washing with TBS-T, membranes were probed with antibodies against TLR9 and IRAK-1 and diluted of 1:3,000 in TBS-T and incubated overnight. After three washes with TBS-T, membranes were treated for $1 \mathrm{~h}$ with HRP-conjugated indicated antibodies diluted to 1:20,000 in TBS-T. After three washes with TBS-T, immunoreactive protein bands were revealed with an enhanced chemiluminescence western blot analysis system (ECL) or ECL Plus. Films were scanned and analysed on a GS7-10 Calibrated Imaging Densitometer equipped with Quantity One v. 4.0.3 software (Bio-Rad, Veenendaal, the Netherlands).

\section{Quantification of NF- $\kappa$ B activity}

NF- $\kappa$ B activation was detected using the Trans-AM NF- $\kappa$ B p65/ NF-кB p50 Transcription Factor Assay Kit (Active Motif, Rixensart, Belgium) according to the manufacturer's instructions. Briefly, $2 \mu \mathrm{g}$ nuclear extract was incubated with an oligonucleotide, containing the NF- $\kappa \mathrm{B}$ consensus site, bound to a 96-well plate. After extensive washes, the NF- $\kappa B$ complexes bound to the oligonucleotide were incubated with an antibody directed against the NF- $\mathrm{KB}$ p65 subunit at a dilution 1:1,000. After washing, the plates were subsequently incubated with a secondary antibody conjugated to horseradish peroxidase 
$(1: 1,000)$, and the peroxidase reaction was quantified at $450 \mathrm{~nm}$ with a reference wavelength of $655 \mathrm{~nm}$.

\section{FACS analysis}

Isolated neutrophils were incubated with CSE (1.5\%) or CpG ODN $(3 \mu \mathrm{M})$ alone or in combination at various time points and then fixed with formaldehyde (1\%) and then permeabilised with permeabilisation buffer (eBioscience) and stained with PEconjugated anti-human TLR9 Ab (eB72-1665) or a PE-conjugated rat $\mathrm{IgG}_{2 \mathrm{a}}$ class-matched irrelevant $\mathrm{Ab}$ (eBioscience) as control for $30 \mathrm{~min}$ in permeabilisation buffer on ice. polymorphonuclear neutrophil (PMN), defined as $\mathrm{CD}_{16}{ }^{+} \mathrm{CD}^{-} \mathrm{CD} 19^{-} \mathrm{HLA}^{-} \mathrm{DR}{ }^{-}$cells (all antibodies by ebioscience), were gated at a purity of $>95.2 \%$.

Cells were washed three times with immunofluorescence buffer (PBS 1\%, FCS 1\% and sodium azide 0.1\%) and 10,000 cells were analysed on a FACSCalibur flow cytometer. The results obtained with specific antibodies were compared with those using isotype-matched control antibodies in parallel.

\section{RNA isolation and real-time PCR}

Total RNA for cDNA synthesis was prepared from activated and unactivated control cells at different time-points and then isolated using TRIzol reagent, and reverse transcription was performed in a $20-\mu \mathrm{l}$ reaction with $1 \mu \mathrm{g}$ total RNA, $50 \mathrm{mM}$ Tris$\mathrm{HCl}$ (pH 8), $75 \mathrm{mM} \mathrm{KCl}, 3 \mathrm{mM} \mathrm{MgCl}$, $10 \mathrm{mM}$ dithiothreitol, $500 \mu \mathrm{M}$ each of deoxynucleotide triphosphates and SuperScript III reverse transcriptase at $42^{\circ} \mathrm{C}$ for $1 \mathrm{~h}$. To eliminate DNA contamination, the RNA samples were incubated with DNase I at room temperature for $15 \mathrm{~min}$. For real-time PCR, cDNA was analysed for the expression of TLR9 and $\beta_{2^{-}}$ microglobulin (B2M) genes using Sybergreen Universal PCR Master Mix by using an ABI Prism 7000 Sequence Detection System (Applied Biosystems, Foster City, CA, USA) at $50^{\circ} \mathrm{C}$ for $2 \mathrm{~min}, 95^{\circ} \mathrm{C}$ for $10 \mathrm{~min}$, then 40 cycles of $95^{\circ} \mathrm{C}$ for $15 \mathrm{~s}$ and $60^{\circ} \mathrm{C}$ for $1 \mathrm{~min}$. The sequences for PCR primers were: CXCL8: forward 5'-CTGGCCGTGGCTCTCTTG-3' and reverse 5'-CCTTGGCAAAACTGCACCTT-3', (accession number: NM_000584); TLR9: forward 5'-TGGTGTTGAAGGACAGTTCTCTC-3' and reverse 5'-CACTCGGAGGTTTCCCAGC-3' (accession number: NM_017442); and B2M: forward 5'-CTCCGTGGCCTTAGCTGTG-3' and reverse 5'-TTTGGAGTACGCTGGATAGCCT-3' (accession number: AF072097).

\section{Stable transfection of NF- $\kappa B$ plasmid and NF- $\kappa B$ activity assay}

TLR9 stably transfected HEK 293 cells were maintained in DMEM containing $10 \% \mathrm{FCS}$ in $5 \% \mathrm{CO}_{2}$ at $37^{\circ} \mathrm{C}$. Cells were split on a 6 -well dish or $60 \mathrm{~mm}$ dish at density $0.75 \times 10^{5} \mathrm{cells} \cdot$ dish $^{-1}$. After $18 \mathrm{~h}$, cells were transfected with p-nifty $2 \times$ NF-kB SEAP plasmid using Lipofectamine Plus reagent (Invitrogen) according to the manufacturer's instructions. The total amount of DNA was adjusted using an empty vector, pcDNA3 (Invivogen). Cells were washed and cultured with $1 \mathrm{mg} \cdot \mathrm{mL}^{-1}$ Zeocin for 4 weeks. At week 5 of transfection, cells were activated with CpG ODN $(3 \mu \mathrm{M})$ and or CSE $(1.5 \%)$ for $9 \mathrm{~h}$ for detection of SEAP by supernatant. For determination of SEAP as an indicator for NF- $\kappa B$ activity, the supernatants were subjected to QUANTIBlue $^{\mathrm{TM}}$ reagent as instructed by the manufacturer. SEAP levels were determined spectrophotometrically at 620-655 nm.

\section{Statistical analysis}

Experimental results are expressed as mean \pm SEM. Results were tested statistically by an unpaired two-tailed t-test or oneway ANOVA, followed by Newman-Keuls test for comparing all pairs of groups. Analyses were performed by using GraphPad Prism (version 2.01). Results were considered statistically significant when $\mathrm{p}<0.05$.

\section{RESULTS}

\section{CSE and CpG-induces CXCL8 release via the generation of NO and ROS stress}

CpG ODN induced the production of CXCL8 release by neutrophils in a concentration-dependent manner (fig. 1a). In all subsequent experiments, a sub-maximal concentration of $3 \mu \mathrm{M}$ CpG ODN was selected. CSE (1.5\%) also induced CXCL8 release from human neutrophils (fig. $1 b$ and $c$ ). This effect on CXCL8 release was selective as CSE did not significantly induce the release of cytokines, such as TNF- $\alpha$ and IL- 6 , and chemokines, such as CCL2, CXCL10 and CCL11 (data not shown). Preincubation of the neutrophils with L-NAME or NAC (inhibitors of $\mathrm{NO}$ or ROS generation, respectively) inhibited the release of both CSE- and CPG ODN ( $3 \mu \mathrm{M})$ induced CXCL8 production back to baseline (fig. $1 \mathrm{~b}$ and $\mathrm{c}$ ). Pre-incubation of cells with the combination of sub-maximal concentrations of NAC and LNAME further suppressed the CXCL8 production (fig. 1d) compared with that seen with either treatment alone, although the levels did not return to baseline.

Furthermore, CSE (1.5\%; fig. 1e and f) and CpG ODN ( $3 \mu \mathrm{M}$; fig. If and g) enhanced intracellular ROS and NO production.

\section{CSE activates TLR9 signalling}

To explore whether CSE regulates CXCL8 production via TLR9, neutrophils were pre-treated with chloroquine, an inhibitor of TLR activation pathways, particularly TLR9. Chloroquine $\left(1-50 \mathrm{mg} \cdot \mathrm{mL}^{-1}\right)$ concentration-dependently attenuated the release of CXCL8 induced by CSE (fig. 2a). Chloroquine was cytotoxic at concentrations $\geqslant 10 \mathrm{mg} \cdot \mathrm{mL}^{-1}$ (fig. 2b). Next, to examine specific activation of TLR9 signalling by CSE, the effects of the TLR9-inhibitory ODN on CXCL8 release was investigated [29]. Inhibitory ODN suppressed the CSE-induced CXCL8 production in a concentration-dependent manner (fig. 2c). We then determined the effects of neutralising TLR2 and TLR4 antibodies on CXCL8 release by human neutrophils. As shown in figure $2 \mathrm{~d}$, a neutralising antibody against TLR4 significantly attenuated the release of CXCL8 by human neutrophils. A combination of chloroquine and the neutralising antibody against TLR4 further suppressed the release of CSE-induced CXCL8 production (fig. 2d).

Further evidence for TLR9 involvement was suggested by the effects of CSE on TLR9 in a stably transfected HEK 293 cell line. CSE induced the release of CXCL8 in TLR9 stably transfected HEK 293 cells but not in TLR9 null cells (fig. 3a and $b$ ). CpG ODN served as a positive control for activation of TLR9 pathways (fig. 3). Components of cigarette smoke, such as nicotine and acrolein, may also modulate TLR9 signalling but we were unable to demonstrate any production of CXCL8 by these compounds in TLR9 stably transfected HEK 293 cells (data not shown). 

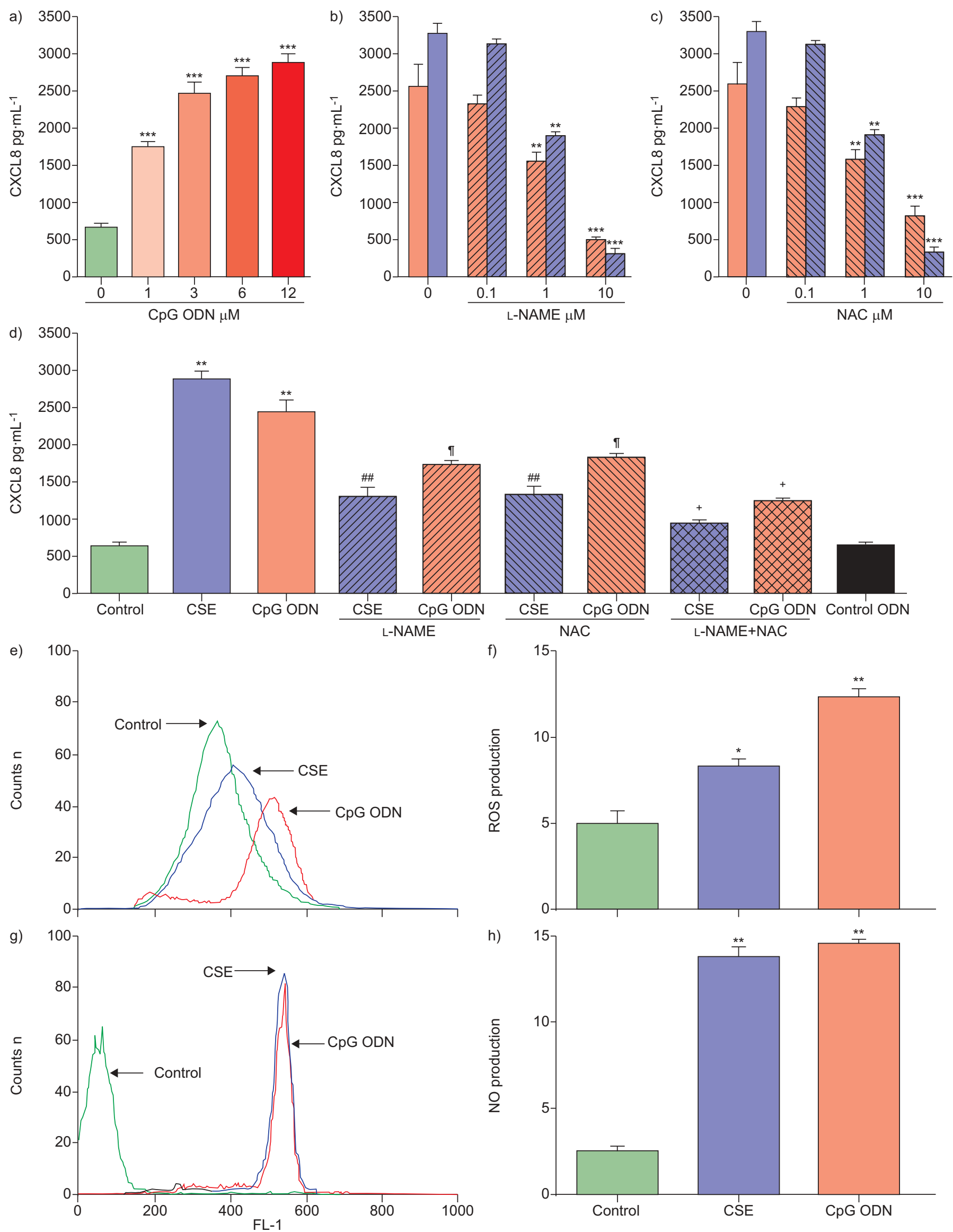
FIGURE 1. Effects of $N^{G}$-nitro-L-arginine methyl ester (L-NAME) and $N$-acetyl-cysteine (NAC) on the release of CXC chemokine ligand (CXCL)8 and generation of reactive oxygen species (ROS) and nitric oxide (NO) induced by cigarette smoke extract (CSE) and CpG oligonucleotides (ODN) of human neutrophils. Neutrophils (10 ${ }^{6}$ cells. $\mathrm{mL}^{-1}$ ) were seeded onto 96-well plates and placed in low-serum (1\% fetal calf serum) medium and a) stimulated with various concentration of CpG ODN ( $(\square)$ for $9 \mathrm{~h}(\square:$ control); or

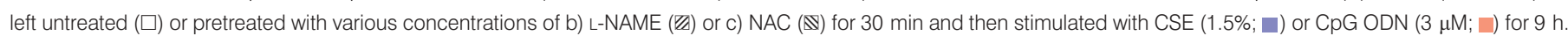
Levels of CXCL8 in supernatants were measured by ELISA and data are expressed as $\mathrm{pg} \cdot \mathrm{mL}^{-1}$. Assays were performed three times in duplicate. Data are presented as mean $\pm \operatorname{SEM}(n=3) . a)^{* *}: p \leqslant 0.001$ compared with control. $b$ and $\left.c\right) * *: p \leqslant 0.01 ; * * *: p \leqslant 0.001$ compared with cells treated with L-NAME and NAC in activated cells with CSE

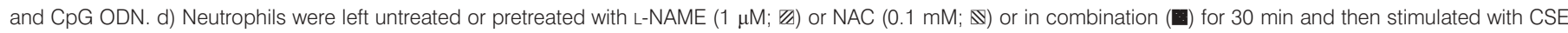
$(1.5 \%$; 1 ) or CpG ODN $(3 \mu \mathrm{M}$; $\square)$ or control ODN $(5 \mu \mathrm{M})$ for $9 \mathrm{~h}$. Levels of CXCL8 in supernatants were measured by ELISA and data are presented as mean \pm SEM ( $\mathrm{n}=3$ ). **: $p \leqslant 0.01$ compared with control; \#\#: $p \leqslant 0.01$ compared with CSE; ${ }^{\natural}: p \leqslant 0.05$ compared with CpG ODN; ${ }^{+}: p \leqslant 0.05$ compared to L-NAME alone or NAC alone. e-h) Neutrophils ( $10^{6}$ cells) were incubated with CSE $(1.5 \%$; $)$ or CpG ODN ( $\left.3 \mu \mathrm{M} ; \square\right)$ for $5 \mathrm{~h}$. Cells were washed and preincubated with e and f) $10 \mu \mathrm{M}$ redox-sensitive dye DCFH-DA (for ROS) or $\mathrm{g}$ and h) $5 \mu \mathrm{M}$ of diaminofluorescein diacetate (for NO) for 20 min at $37^{\circ} \mathrm{C}$ in PBS containing $1 \% \mathrm{BSA}$, in the dark. Generation of intracellular ROS and NO were determined by FACS analysis as described in the Material and Methods section and are representative of three independent experiments using polymorphonuclear neutrophil from different donors. The mean fluorescent intensity (MFI) of the groups is presented. Analyses of MFI from three independent experiments are presented as mean \pm SEM in parts $f$ and $h$ for ROS and NO production, respectively. *: $p \leqslant 0.05 ; * *: p \leqslant 0.01$ compared with control.

\section{CSE modulates TLR9 expression in neutrophils}

TLR9 is predominantly expressed in intracellular vesicles [17]. Neutrophils were first fixed and permeabilised, and subsequently stained with a PE-conjugated anti-TLR9 Ab or isotype IgG control. After short exposure ( $5 \mathrm{~h}$ ) to CSE, the intracellular expression of TLR9 was upregulated (fig. 4a) whereas after overnight exposure (24 h) TLR9 expression was downregulated (fig. 4b). Moreover, CSE did not induce surface expression of TLR9 (data not shown). This regulation of TLR9 protein expression paralleled with expression of mRNA (fig. 5a). Similar results were observed with CXCL8 mRNA expression (fig. 5b). Both NAC (1 mM) and L-NAME $(0.1 \mu \mathrm{M})$ inhibited CSE and CpG ODN-enhanced intracellular TLR9 protein expression (fig. 5c).

\section{CSE induces activation of NF- $\kappa B$ via TLR9 signalling}

In human neutrophils, CSE increased the activity of NF- $\kappa B$ in the nucleus and pretreatment with NAC, L-NAME and the TLR9 inhibitory ODN suppressed NF- $\kappa$ B activity induced by CSE (fig. 6a).

TLR activation triggers a signalling cascade that involves sequential recruitment and activation of IRAK-4 and -1 [30]. Phosphorylation of IRAK-1, in turn, enables recruitment and phosphorylation of the TAK1 complex which then dissociates, along with TRAF6, from the receptor complex. TRAF6 and IRAK-1 are ubiquitinated and degraded, enabling induction of TAK1 kinase activity and activation of NF- $\kappa B$ and the upregulation of proinflammatory gene transcription [30].

We, therefore, investigated whether CSE or CpG ODN affected IRAK-1 expression and the association of IRAK-1 with TRAF6. IRAK-1 underwent partial degradation upon stimulation with CSE and CpG ODN as evidenced in immunoblots of whole-cell extracts (fig. 6b). Pre-incubation of CSE-stimulated cells with the blocking inhibitory ODN abrogated IRAK-1 degradation. IRAK-1 was associated with TRAF6 in resting neutrophils (fig. 6c, lane 1). However, this association was lost following incubation of cells with CPG ODN and CSE for $10 \mathrm{~min}$ (fig. 6c, lanes 2 and 3, respectively) in agreement with the notion that IRAK becomes dissociated and degraded. The inhibitory ODN abrogated the dissociation and degradation of IRAK-1 (fig. 6c, compare lanes 3 and 4).

Next, as supportive evidence for CSE actions on the TLR9 pathway,

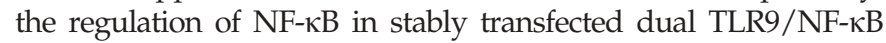
reporter HEK 293 cells was investigated. The production of SEAP, an indicator of NF- $\kappa \mathrm{B}$ activation in this system, was significantly enhanced after CSE incubation (fig. 7a). Similar results were obtained with $\mathrm{CpG}$ ODN as a positive control. The response was specific for TLR9 signalling since SEAP production was not increased by CSE or CpG in HEK 293 lacking TLR9 (fig. 7b).

\section{DISCUSSION}

The present study demonstrates that CSE induces the production of CXCL8 from human neutrophils via TLR9 signalling through a ROS- and NO-dependent mechanism. Chloroquine and the TLR9 inhibitory ODN attenuated the release of CXCL8-induced by CSE. Moreover, inhibitory ODN abrogated the induction of CXCL8 mRNA by CSE and inhibitory ODN also blocked TRAF6 and IRAK1 association and degradation and subsequent induction of NF- $\mathrm{\kappa B}$ activity induced by CSE. Due to the short span of neutrophils in culture and their low transfection efficiency, we were not able to modulate TLR9 expression or signalling pathways in these cells. In support of our hypothesis, we report that CSE was able to induce CXCL8 release in HEK 293 cells stably transfected with TLR9 but not in cells devoid of TLR9. Internalisation and endosomal maturation have been shown to be required for CPG DNA to activate TLR9 signalling in immune cells [31, 32]. Chloroquine, which effectively blocks endosomal maturation, significantly inhibited the CSE-induced increase of CXCL8 production in neutrophils, indicating a similar signalling pathway as CpG ODN.

In COPD patients, an increase of proinflammatory cytokines and chemokines including TNF- $\alpha$ and CXCL8 has been reported, and these mediators play an important role in establishing and maintaining the inflammatory condition, characterised by high local neutrophilia [7]. Importantly, neutrophils constitutively express TLR9 [33-35]. TLRs have been intensely studied in the context of microbial challenges to inflammatory and immune cells, but their critical role in non-infectious challenges has only recently emerged. TLRs are the best characterised pattern recognition receptors in neutrophils in which lies most of their pathogen recognition capacity [33]. Moreover, TLRs recognise distinct structural components of pathogens and trigger a signalling cascade that involves association of its intracellular Toll-IL-1R (TIR)-signalling domain with the adaptor molecule MyD88 [36]. A sequential recruitment and activation of IRAK-4 and -1 then occurs [37]. Phosphorylation of IRAK-1, in turn, enables recruitment and phosphorylation of the TAK1 complex which then dissociates, along with TRAF6, from the receptor complex. TRAF6 and IRAK-1 are ubiquitinated and degraded enabling induction of TAK1 kinase activity and activation of 

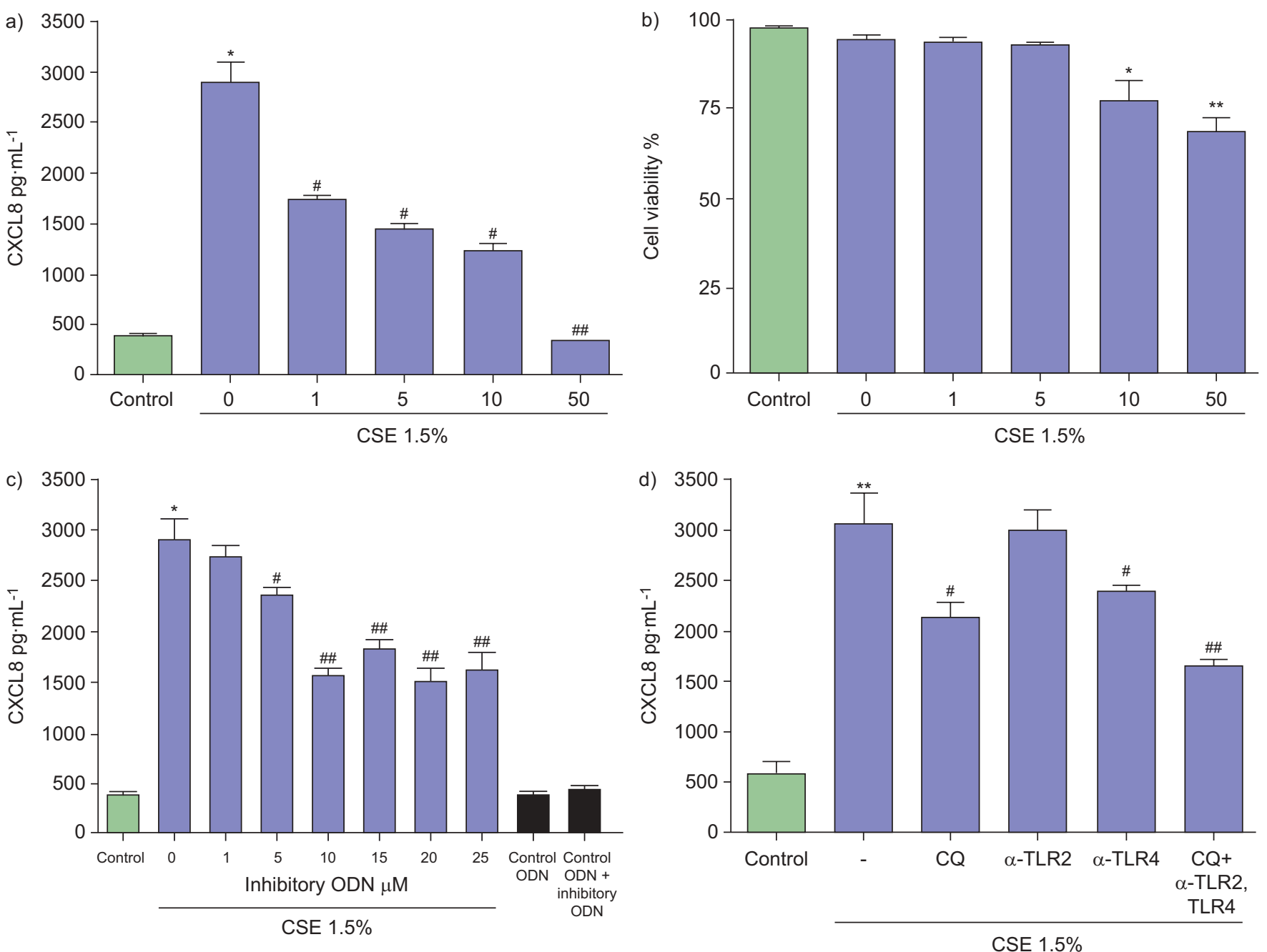

FIGURE 2. Effects of chloroquine (CQ), Toll-like receptor (TLR)9 inhibitory oligonucleotide (ODN) and blocking antibodies on CXC chemokine ligand (CXCL)8 release, induced by cigarette smoke extract (CSE) and CpG ODN of human neutrophils. Neutrophils ( $\left.10^{6} \mathrm{cells} \cdot \mathrm{mL}^{-1}\right)$ were seeded onto $96-$ well plates, placed in low-serum (1\% fetal calf serum) medium and left untreated or pretreated with $a$ and b) CQ (1-50 $\left.\mu \mathrm{g} \cdot \mathrm{mL}^{-1}\right)$, c) blocking inhibitory ODN (1-25 mM) or d) naturalising antibodies for TLR2 and TLR4 $\left(20 \mu \mathrm{g} \cdot \mathrm{mL}^{-1}\right)$ with or without CQ for $30 \mathrm{~min}$ and then activated with CSE (1.5\%; $\left.{ }^{-}\right)$or control ODN $(5 \mathrm{mM})$ for $9 \mathrm{~h}$. Levels of CXCL8 in culture supernatants were measured by ELISA and data are presented in $\mathrm{pg} \cdot \mathrm{mL}^{-1}$. Assays were performed three times in duplicate. b) Viability of the cells after incubation with various concentrations of $\mathrm{CQ}$ was determined by staining of cells with propidium ionide. Data are presented as mean $\pm \operatorname{SEM}(n=3)$. *: $p \leqslant 0.05$ compared with control; ${ }^{*}: p \leqslant 0.01$ compared with control; \#: $p \leqslant 0.05$ compared with CSE;

$\mathrm{NF}-\kappa \mathrm{B}$ and the up-regulation of proinflammatory gene transcription [30]. From this signalling complex, downstream cascades ultimately lead to activation of NF- $\mathrm{KB}$, regulating proinflammatory gene transcription [30]. TLRs are expressed in numerous cells within the airway and can therefore act as important sensors of environmental particulates and gases [23, 38, 39]. TLRs have also been implicated in the pathogenesis and severity of autoimmune [40], cardiac and lung diseases [23, 38]. In accordance with this concept, we and others [17, 23, 41, 42] have shown that cigarette smoke modulates TLR2 and TLR4 expression. In addition, CSE contains LPS [43] which is a potent activator of TLR4 signalling. Using a neutralising antibodies against TLR4 and TLR2, we have shown a partial involvement of TLR4 in CSE-induced CXCL8 expression in primary human neutrophils. Moreover, blocking TLR4 activity in combination with attenuation of TLR9 using chloroquine resulted in a greater decrease in CSE-induced CXCL8 expression. This indicates a degree of cross-talk between TLRs in regulating the response to cigarette smoke. The expression and coupling of receptors in different cell types will affect various signalling pathways, as well as that of NF- $\kappa B$ which may affect the final functional response observed. The fact that there is a residual level of CXCL8 production remaining after blocking TLR4 and TLR9 indicates the involvement of other pathways stimulated by CSE in the control of CXCL8 production.

Interestingly, we have found that CSE up-regulates TLR9 and CXCL8 expression in parallel. Moreover, the up-regulation of TLR9 expression was dependent on ROS and NO generation and reversed by longer-term incubation. The down-regulation of receptor expression by CSE is probably not due to cell toxicity, since the viability of the cells was not affected. Further investigations are required to understand these pathways and also the precise mechanisms that drive TLR activation. 


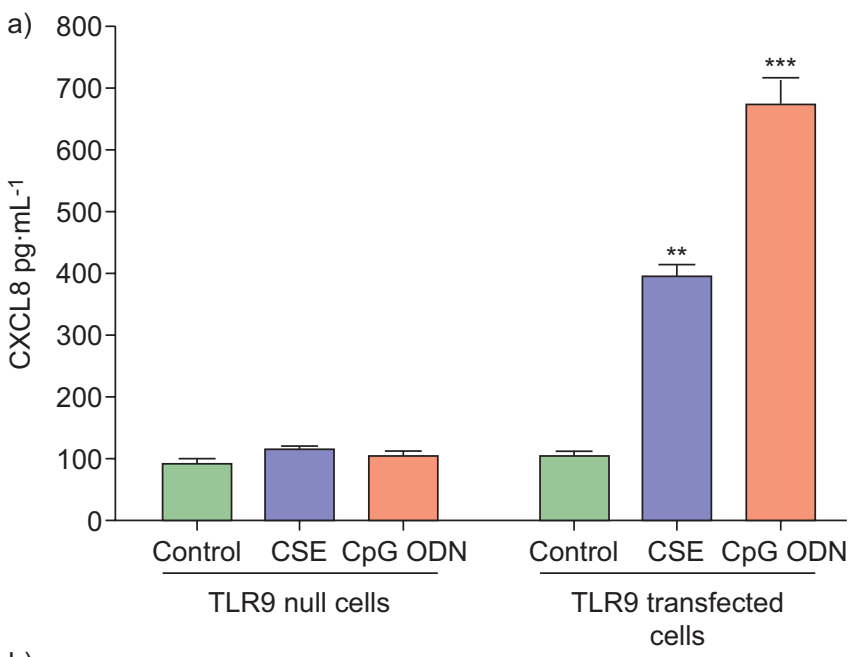

b)
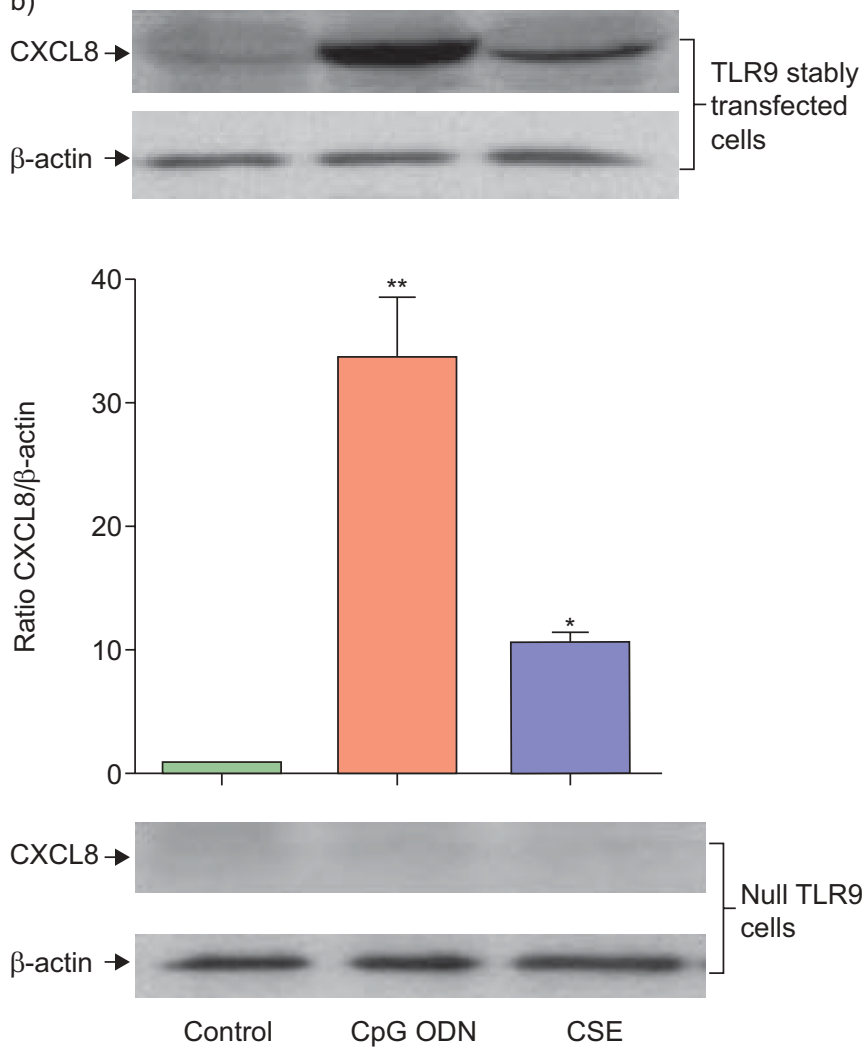

FIGURE 3. Cigarette smoke extract (CSE) induces the production of CXC chemokine ligand (CXCL)8 of Toll-like receptor (TLR) 9 stably transfected human embryonic kidney (HEK) 293 cell lines. a) TLR9 stably transfected HEK 293 and null HEK 293 cells $\left(2 \times 10^{6}\right.$ cells $\left.\cdot \mathrm{mL}^{-1}\right)$ were stimulated with CSE (1.5\%; $)$ and CpG oligonucleotide (ODN; $3 \mu \mathrm{M} ;-1)$ for $9 \mathrm{~h}$. CXCL8 levels in culture supernatants were measured by ELISA and data are presented as $\mathrm{pg} \cdot \mathrm{mL}^{-1}$. Assays were performed three times in duplicate. Data are presented as mean \pm SEM $(n=3)$. b) TLR9 stably transfected HEK 293 or null cells stimulated for $6 \mathrm{~h}$ with CSE or CpG ODN and after lysis whole extracts subjected to western blot analysis with an anti-CXCL8 antibody or as a background with $\beta$-actin. The ratios of $C X C L 8$ to $\beta$-actin expression from three separate gels are shown in the lower panels. Data are presented as mean \pm SEM of triplicate samples. $*: p<0.05 ; * *: p \leqslant 0.01$; $\star * *: p \leqslant 0.001$ compared with control.
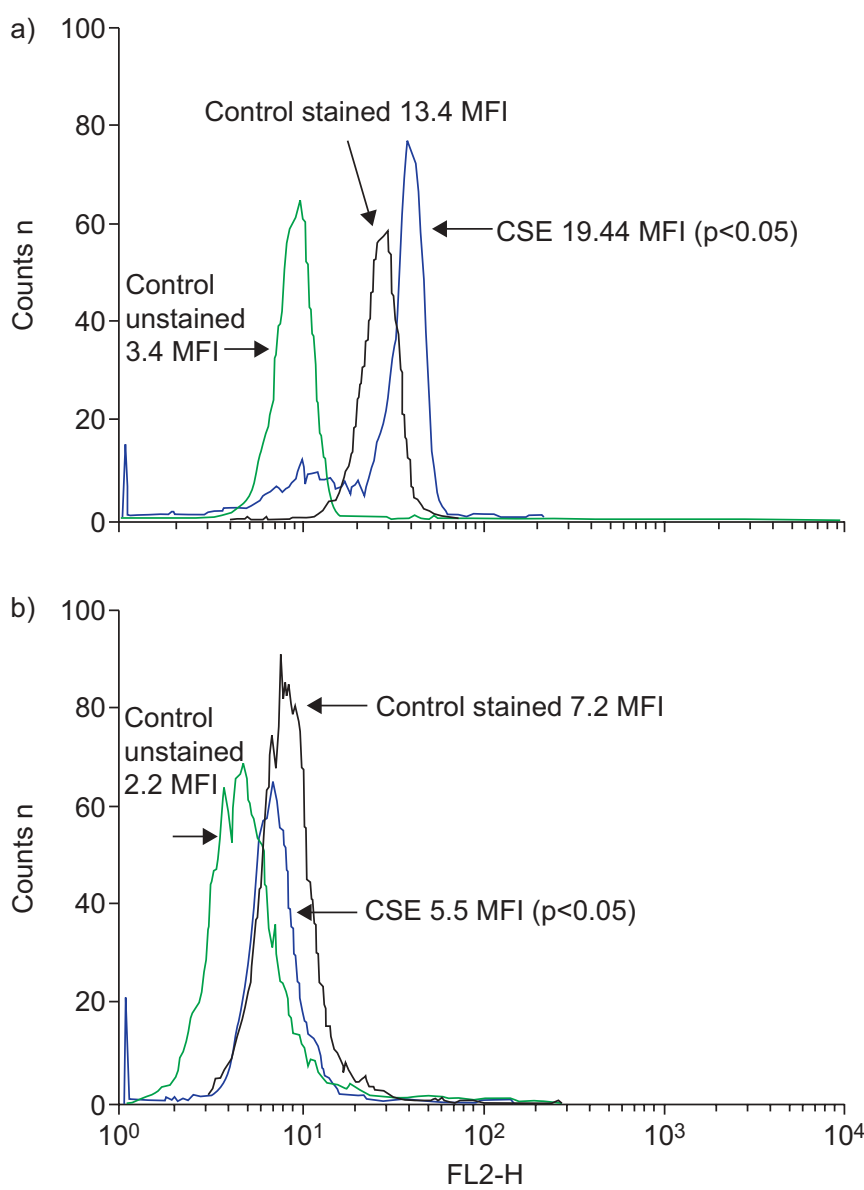

FIGURE 4. Cigarette smoke extract (CSE) regulates Toll-like receptor (TLR)9 receptor expression. Neutrophils $\left(10^{6} \mathrm{cells} \cdot \mathrm{mL}^{-1}\right)$ were activated with CSE $(1.5 \%)$ or CpG oligonucleotide ( $3 \mu \mathrm{M})$ for a) $5 \mathrm{~h}$ and b) $24 \mathrm{~h}$. Then, cells were permeabilised and stained with an anti-human TLR9 antibody or an isotype control (immunoglobulin G) for $30 \mathrm{~min}$ in the dark. After two washes with cold PBS, the intracellular levels of TLR9 were determined by flow cytometry (using fluorescence-activated cells sorting). The results are representative for four experiments using neutrophils from different donors. Green lines indicated for control unstained cells, black lines indicated for control stained cells and blue lines indicated for cells treated with CSE. The mean fluorescent intensity (MFI) are presented.

TLR9, is to date the best-characterised sensor for bacterial DNA, containing short sequences of unmethylated CpG ODN motifs [38], and TLR9 stimulation results in alterations in cellular redox balance, peroxynitrite formation and activation NF-kB [44-49]. Taken together, it can be concluded that CSE plays a crucial role in the induction of TLR9 expression and activation through generation of ROS and NO and the subsequent release of CXCL8 in neutrophils. TLR4 is also implicated in this effect and it is likely that other TLRs may also modulate CXCL8 production by CSE in an analogous manner.

Accumulating data indicated that cigarette smoke induces the production of free radicals in cells [47, 48]. Free radicals in turn are able to activate a number of key pro-inflammatory transcription factors, including NF-KB and AP-1 [49, 50]. Indeed, CSE induced the cellular production of $\mathrm{NO}$ and ROS which could be protected by L-NAME and NAC. Inhibitory 

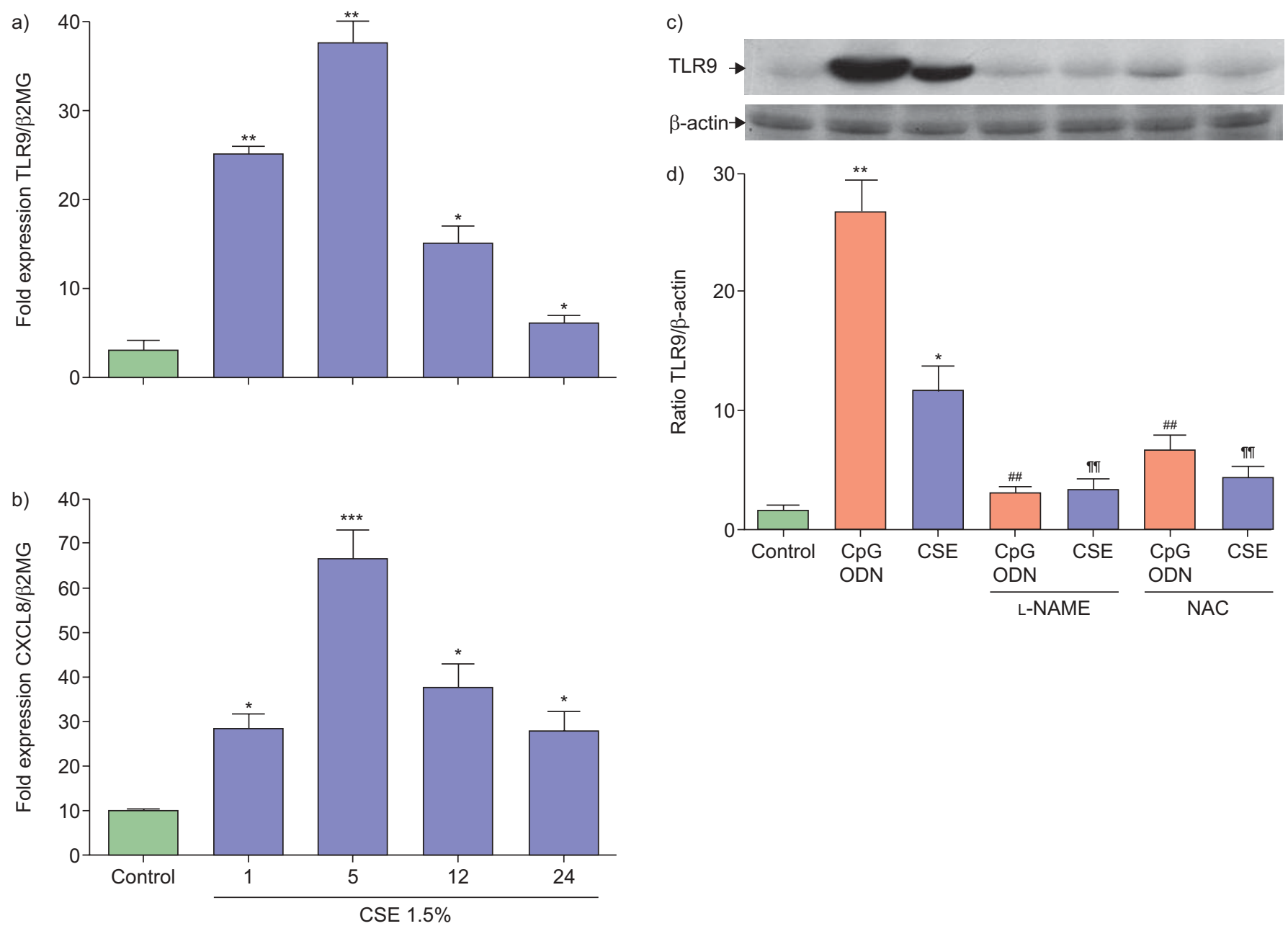

FIGURE 5. Cigarette smoke extract (CSE) modulates mRNA and intracellular expression levels of Toll-like receptor (TLR)9 and CXC chemokine ligand (CXCL) 8 . Neutrophils $\left(5 \times 10^{6}\right.$ cells) were treated with CSE $(1.5 \%$; $)$ for $1,5,12$ and $24 \mathrm{~h}$. Total RNA was isolated and after conversion to cDNA was subjected to real-time PCR analysis for mRNA expression for a) TLR9 or b) CXCL8, as a ratio of $\beta_{2}$-macroglobulin expression ( $\left.\beta 2 M G\right)$. Data are presented as mean \pm SEM from three experiments. $*: p<0.05,{ }^{* *}: p \leqslant 001$ compared with control. c) Neutrophils $\left(5 \times 10^{6}\right.$ cells) were activated with CSE $(1.5 \%)$ or $\mathrm{CpG}$ oglionucleotide (ODN; $\left.3 \mu \mathrm{M}\right)$ for $5 \mathrm{~h}$ in the presence or absence of $N$-acetylcysteine (NAC; $1 \mathrm{mM}$ ) or $N^{G}$-nitro-L-arginine methyl ester (L-NAME; $0.1 \mu \mathrm{M}$ ) and then lysed with lysis buffer. The expression of TLR9 and $\beta$-actin was detected using $50 \mathrm{mg}$ of whole cell lysates by western blot analysis. Blots are representative of three independent experiments showing similar results. d) The ratio of TLR9 to $\beta$-actin expression from three separate gels is shown. Data are presented as mean \pm SEM of triplicate samples. *: $p<0.05 ; * *: p \leqslant 0.01 ; * *$ : $p \leqslant 0.001$ compared with control; \#\#: $p<0.01$ compared with CpG ODN; ${ }^{\top \%}: p<0.01$ compared with CSE alone.

ODNs, that block TLR9 activation, attenuated CSE-induced $\mathrm{NF}-\kappa \mathrm{B}$ activity and upstream events in TLR9 signalling including the effects on TRAF and IRAK-1. Furthermore, CSE activated NF- $\mathrm{B}$ in TLR9 stably transfected, but not untransfected, HEK 293 cells.

The precise component(s) of CSE that stimulate TLR9 and the mechanism by which it acts remains to be elucidated. It is possible that CSE contains CPG ODN which can directly stimulate TLR9 $[44,46,51]$. However, the differential effect of CSE and CPG ODN on ROS production suggests that this may not be the case. It has been suggested that ROS may activate TLRs either directly or indirectly $[52,53]$ potentially through an effect on modifying key residues within the TLR complex [54]. Furthermore, future studies are needed to determine whether the ROS is derived directly from CSE or as a result of CSE activation of neutrophils.
Several studies have demonstrated that activation of TLR9 by CpG ODN could prevent allergic airway inflammation and airway hypersensitivity reaction, suggesting a potential therapeutic application of TLR9 signalling in asthma [55]. In support of this, children who were exposed to parental smoking and those who took up cigarette smoking themselves, have a lower incidence of atopy to a range of common inhaled allergens [56]. Intriguingly, in the current study we show that CSE increases the expression and activity of TLR9 in a temporal manner which may contribute to the prevention of allergic reactions or the resolution of inflammatory responses.

The role of the neutrophils in COPD is complex and it is unclear what the predominant driving force for their activation is in the human airway. Here we report that CSE directly stimulates neutrophil functions but we cannot determine what is the initial event that occurs in vivo? It is possible that inhaled cigarette 

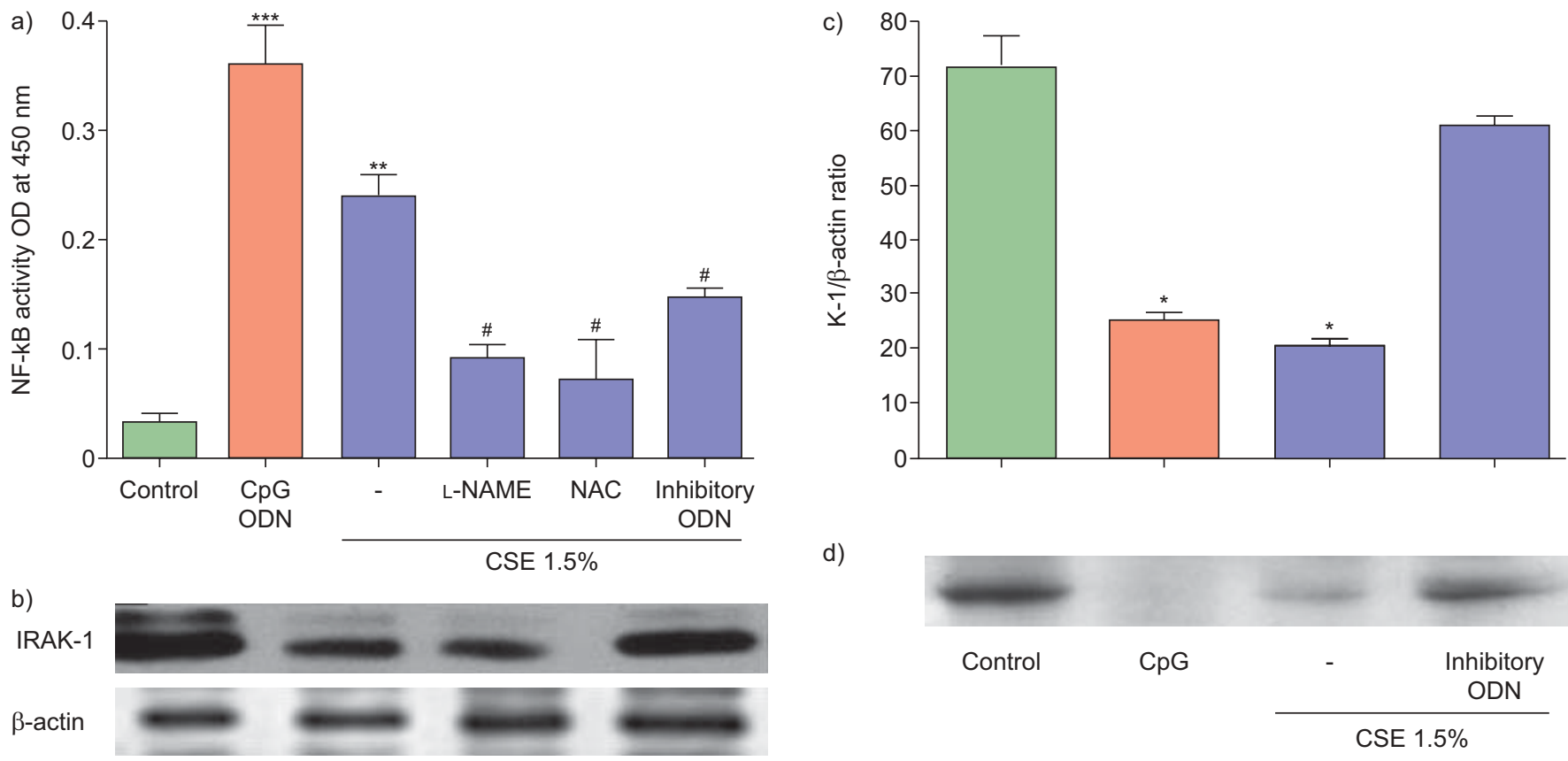

d)

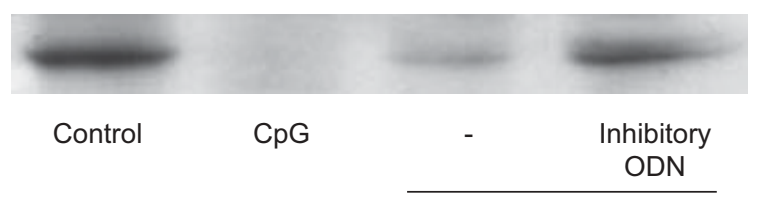

CSE $1.5 \%$

FIGURE 6. Cigarette smoke extract (CSE) activates Toll-like receptors and nuclear factor (NF)-kB pathways. Neutrophils $\left(5 \times 10^{6}\right.$ cells) were pretreated with inhibitory

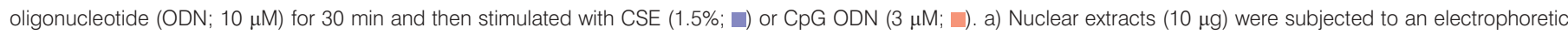
mobility shift assay reaction for detection of NF- $\mathrm{KB}$ activity as described in the Materials and Methods section. Data are presented as mean \pm SEM and are representative from one of five independent experiments. ${ }^{*}: p<0.05,{ }^{* *}: p \leqslant 001$ compared with control. ${ }^{*}: p \leqslant 0.05$ compared with CSE. b) Immunoblots of whole cell extracts obtained from neutrophils $\left(15 \times 10^{6}\right.$ cells) pretreated with inhibitory ODN $(10 \mu \mathrm{M})$ and then stimulated with CSE (1.5\%; $\left.\square\right)$ or CpG ODN $(3 \mu \mathrm{M}$; $\square)$ for 30 min revealed with a rabbit polyclonal anti-interleukin-1R-associated kinase (IRAK)-1 antibody. Immunoblots are representative of at least three independent experiments. After stripping the blots, the membranes were incubated with $\beta$-actin as a housekeeping protein and visualised using enzymatic chemiluminescence. The ratio of IRAK-1 to $\beta$-actin expression from three separate gels is shown in the lower panels. Data are presented as mean \pm SEM of triplicate samples. ${ }^{*}: p<0.05$ compared with control. d) Neutrophils (10 ${ }^{6}$ cells) were pretreated with inhibitory ODN and then stimulated with CSE or CpG ODN for $10 \mathrm{~min}$. Cells were lysed and IRAK-1 was immunoprecipitated from the supernatants using antibodies specific for IRAK-1. Proteins were resolved using SDS-PAGE and analysed by western blot with anti-phosphotyrosine monoclonal antibody TRAF-6. OD: optical density; L-NAME: $N_{G-}$ nitro-L-arginine methyl ester; NAC: N-acetylcysteine.

smoke activates neutrophils recruited into the airways as a result of CXCL8 production by epithelial cells, for example, or that cigarette smoke depositing on the airway epithelium could be absorbed and activate circulating neutrophils which then migrate to the airways. The use of animal models will be able to address this in the future.
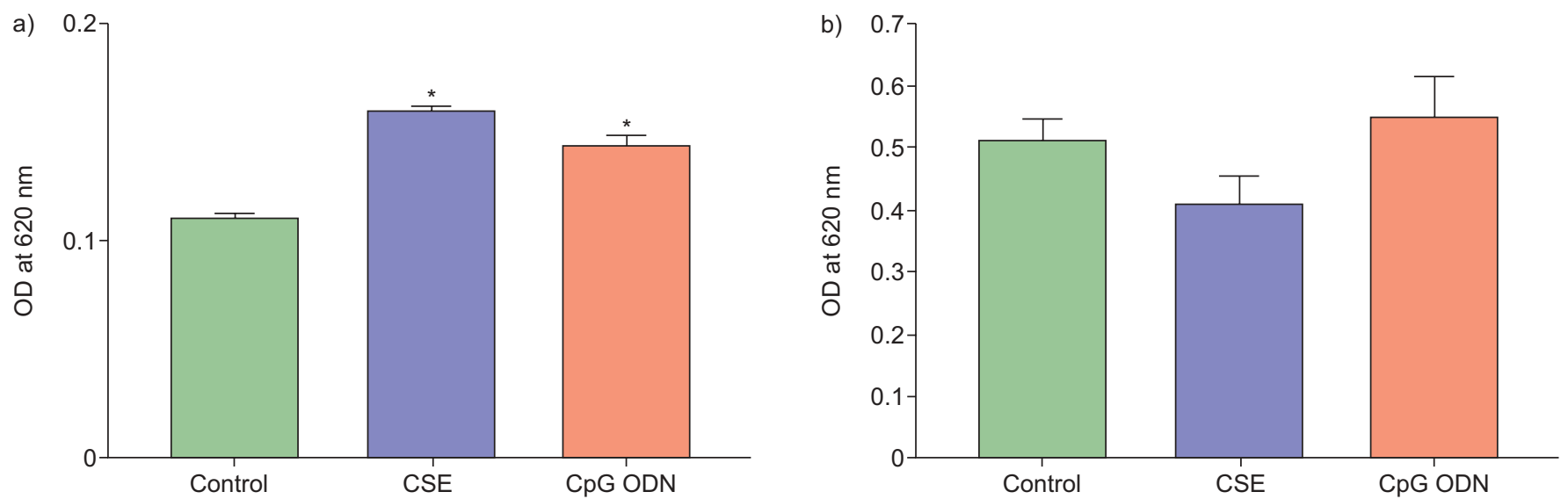

FIGURE 7. Cigarette smoke extract (CSE) activates nuclear factor (NF)kB in Toll-like receptor (TLR)9 stably transfected human embryonic kidney (HEK) cells. TLR9, $\mathrm{NFKB} /$ secreted embryonic alkaline phosphatase (SEAP) double stably transfected HEK cells (a) and null, NFKB/SEAP stably transfectd HEK cells (b) were activated with CSE (1.5\%; $)_{\text {) }}$ or $\mathrm{CpG}$ oligonucleotide (ODN; $\left.3 \mu \mathrm{M} ; \square\right)$ for 30 min. Levels of SEAP as a indicator for NF-KB activity in supernatants were measured by QUANTI-Blue ${ }^{\mathrm{TM}}$ reagent (Cayla-InvivoGen Europe, Toulouse, France). Assays were performed three times in duplicate. Data are presented as mean \pm SEM $(n=3)$. *: $p<0.05$ compared with control. 


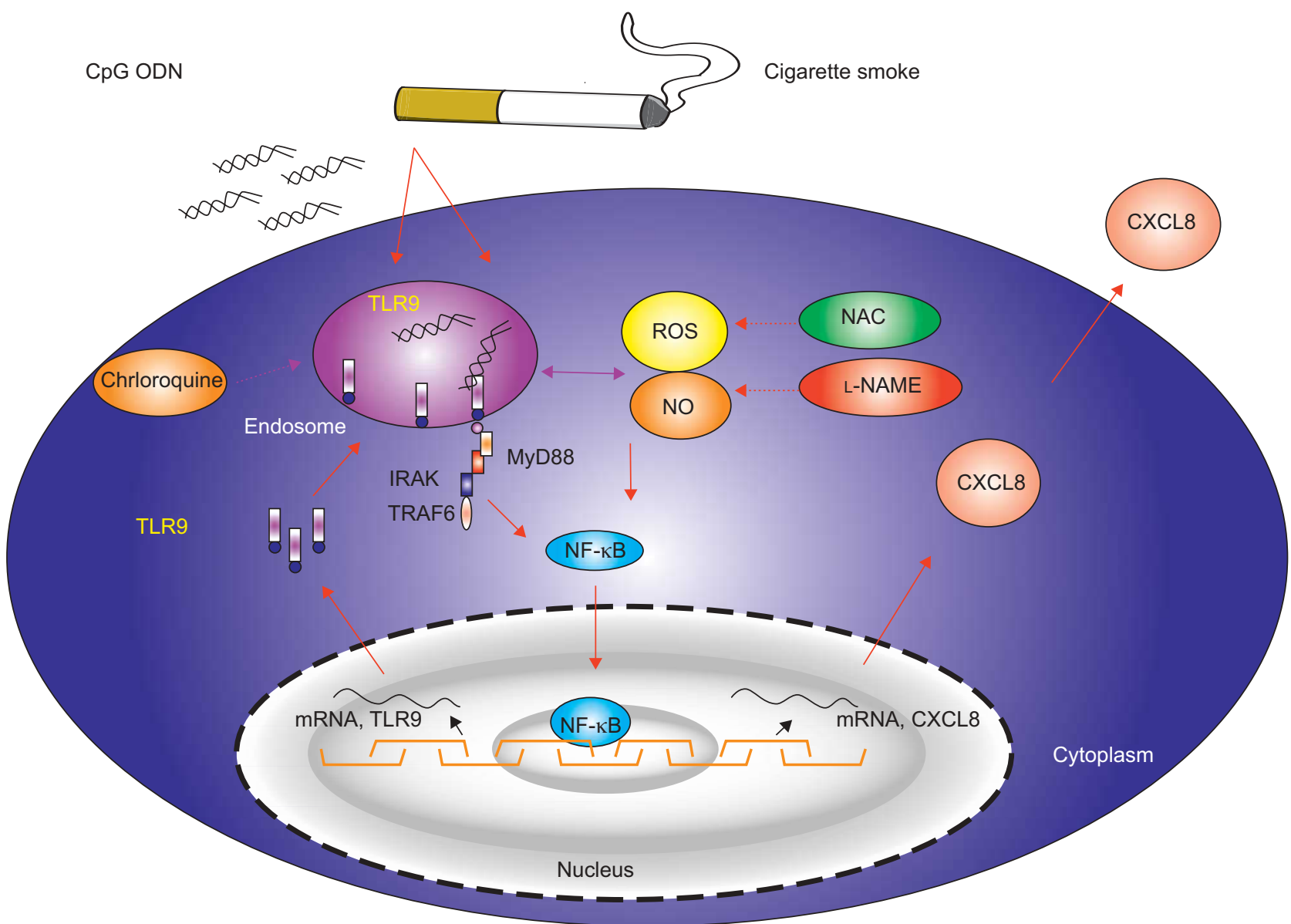

FIGURE 8. Schematic diagram of the induction of CXC ligand (CXCL)8 by human neutrophils via activation of Toll-like receptor (TLR)9 receptors by cigarette smoke. Cigarette smoke extract and CpG oligonucleotide (ODN) activate TLR9 pathway and generate reactive oxygen species (ROS) and NO production. These pathways may phosphorylate interleukin-1 receptor-associated kinase (IRAK) molecules. Following IRAK phosphorylation, the tumour necrosis factor receptor-associated factor 6 (TRAF6) adaptor protein interacts and induces translocation of the transcription factor nuclear factor (NF)- $\mathrm{kB}$ to the nucleus, resulting in transcriptional activation of genes encoding inflammatory mediators (e.g. CXCL8 and TLR9). N-acetylcysteine (NAC), $N^{G}$-nitro-L-arginine methyl ester (L-NAME) and chloroquine act as blockers to the signalling.

The observations and data presented here suggest a link between TLR9 activation and the release of CXCL8 by human neutrophils upon CSE exposure (fig. 8) which may contribute to the accumulation of neutrophils and inflammation within the airways of smokers.

\section{STATEMENT OF INTEREST}

A statement of interest for this study is available from www.erj. ersjournals.com/site/misc/statements.xhtml

\section{ACKNOWLEDGEMENTS}

This study was performed within the framework of Dutch Top Institute Pharma (project numbers D1.101). I.M. Adcock is supported by the Wellcome Trust.

\section{REFERENCES}

1 Mathers CD, Loncar D. Projections of global mortality and burden of disease from 2002 to 2030. PLoS Med 2006; 3: e442.

2 Tsoumakidou M, Demedts IK, Brusselle GG, et al. Dendritic cells in chronic obstructive pulmonary disease: new players in an old game. Am J Respir Crit Care Med 2008; 177: 1180-1186.
3 Hellermann GR, Nagy SB, Kong X, et al. Mechanism of cigarette smoke condensate-induced acute inflammatory response in human bronchial epithelial cells. Respir Res 2002; 3: 22.

4 Qiu Y, Zhu J, Bandi V, et al. Biopsy neutrophilia, neutrophil chemokine and receptor gene expression in severe exacerbations of chronic obstructive pulmonary disease. Am J Respir Crit Care Med 2003; 168: 968-975.

5 Hogg JC, Chu F, Utokaparch S, et al. The nature of small-airway obstruction in chronic obstructive pulmonary disease. $N$ Engl J Med 2004; 350: 2645-2653.

6 Pauwels RA, Rabe KF. Burden and clinical features of chronic obstructive pulmonary disease (COPD). Lancet 2004; 364: 613-620.

7 Barnes PJ. Mediators of chronic obstructive pulmonary disease. Pharmacol Rev 2004; 56: 515-548.

8 Rahman I, MacNee W. Role of oxidants/antioxidants in smokinginduced lung diseases. Free Radic Biol Med 1996; 21: 669-681.

9 Rustemeier K, Stabbert R, Haussmann HJ, et al. Evaluation of the potential effects of ingredients added to cigarettes. Part 2: chemica composition of mainstream smoke. Food Chem Toxicol 2002; 40: 93-104.

10 Pauwels RA, Buist AS, Calverley PM, et al. Global strategy for the diagnosis, management, and prevention of chronic obstructive pulmonary disease. NHLBI/WHO Global Initiative for Chronic Obstructive Lung Disease (GOLD) Workshop summary. Am J Respir Crit Care Med 2001; 163: 1256-1276. 
11 Slebos DJ, Ryter SW, van der Toorn M, et al. Mitochondrial localization and function of heme oxygenase- 1 in cigarette smokeinduced cell death. Am J Respir Cell Mol Biol 2007; 36: 409-417.

12 Sopori M. Effects of cigarette smoke on the immune system. Nat Rev Immunol 2002; 2: 372-377.

13 Holt PG, Keast D. Environmentally induced changes in immunological function: acute and chronic effects of inhalation of tobacco smoke and other atmospheric contaminants in man and experimental animals. Bacteriol Rev 1977; 41: 205-216.

14 Yang SR, Chida AS, Bauter MR, et al. Cigarette smoke induces proinflammatory cytokine release by activation of NF- $\mathrm{KB}$ and posttranslational modifications of histone deacetylase in macrophages. Am J Physiol Lung Cell Mol Physiol 2006; 291: L46-L57.

15 Miki K, Miki M, Okano Y, et al. Cigarette smoke-induced acute eosinophilic pneumonia accompanied with neutrophilia in the blood. Intern Med 2002; 41: 993-996.

16 Masubuchi T, Koyama S, Sato E, et al. Smoke extract stimulates lung epithelial cells to release neutrophil and monocyte chemotactic activity. Am J Pathol 1998; 153: 1903-1912.

17 Karimi K, Sarir H, Mortaz E, et al. Toll-like receptor-4 mediates cigarette smoke-induced cytokine production by human macrophages. Respir Res 2006; 7: 66.

18 Akira S, Takeda K. Toll-like receptor signalling. Nat Rev Immunol 2004; 4: 499-511.

19 Akira S, Sato S. Toll-like receptors and their signalling mechanisms. Scand J Infect Dis 2003; 35: 555-562.

20 Jozsef L, Khreiss T, El Kebir D, et al. Activation of TLR-9 induces IL-8 secretion through peroxynitrite signalling in human neutrophils. J Immunol 2006; 176: 1195-1202.

21 Maes $T$, Bracke KR, Vermaelen KY, et al. Murine TLR4 is implicated in cigarette smoke-induced pulmonary inflammation. Int Arch Allergy Immunol 2006; 141: 354-368.

22 Doz E, Noulin N, Boichot E, et al. Cigarette smoke-induced pulmonary inflammation is TLR4/MyD88 and IL-1R1/MyD88 signalling dependent. J Immunol 2008; 180: 1169-1178.

23 Zhang $X$, Shan $P$, Jiang G, et al. Toll-like receptor 4 deficiency causes pulmonary emphysema. J Clin Invest 2006; 116: 3050-3059.

24 Mortaz E, Rad MV, Johnson M, et al. Salmeterol with fluticasone enhances the suppression of IL-8 release and increases the translocation of glucocorticoid receptor by human neutrophils stimulated with cigarette smoke. J Mol Med 2008; 86: 1045-1056.

25 Kuijpers TW, Tool AT, van der Schoot CE, et al. Membrane surface antigen expression on neutrophils: a reappraisal of the use of surface markers for neutrophil activation. Blood 1991; 78: 1105-1111.

26 Zou W, Amcheslavsky A, Bar-Shavit Z. CpG oligodeoxynucleotides modulate the osteoclastogenic activity of osteoblasts via Tolllike receptor 9. J Biol Chem 2003; 278: 16732-16740.

27 Amer J, Goldfarb A, Fibach E. Flow cytometric measurement ofreactive oxygen species production by normal and thalassaemic red blood cells. Eur J Haematol 2003; 70: 84-90.

28 Jozsef L, Zouki C, Petasis NA, et al. Lipoxin A4 and aspirintriggered 15-epi-lipoxin A4 inhibit peroxynitrite formation, NF$\kappa \mathrm{B}$ and AP-1 activation, and IL-8 gene expression in human leukocytes. Proc Natl Acad Sci USA 2002; 99: 13266-13271.

29 Stunz LL, Lenert P, Peckham D, et al. Inhibitory oligonucleotides specifically block effects of stimulatory $\mathrm{CpG}$ oligonucleotides in $\mathrm{B}$ cells. Eur J Immunol 2002; 32: 1212-1222.

30 Jefferies CA, O'Neill LA. Bruton's tyrosine kinase (Btk)-the critical tyrosine kinase in LPS signalling? Immunol Lett 2004; 92: 15-22.

31 Krieg AM. Direct immunologic activities of CpG DNA and implications for gene therapy. J Gene Med 1999; 1: 56-63.

32 Ahmad-Nejad P, Hacker H, Rutz M, et al. Bacterial CpG-DNA and lipopolysaccharides activate Toll-like receptors at distinct cellular compartments. Eur J Immunol 2002; 32: 1958-1968.

33 Parker LC, Whyte MK, Dower SK, et al. The expression and roles of Toll-like receptors in the biology of the human neutrophil. J Leukoc Biol 2005; 77: 886-892.
34 Muzio M, Bosisio D, Polentarutti N, et al. Differential expression and regulation of toll-like receptors (TLR) in human leukocytes: selective expression of TLR3 in dendritic cells. J Immunol 2000; 164: 5998-6004.

35 Kokkinopoulos I, Jordan WJ, Ritter MA. Toll-like receptor mRNA expression patterns in human dendritic cells and monocytes. Mol Immunol 2005; 42: 957-968.

36 Akazawa T, Masuda H, Saeki Y, et al. Adjuvant-mediated tumor regression and tumor-specific cytotoxic response are impaired in MyD88-deficient mice. Cancer Res 2004; 64: 757-764.

37 Janssens S, Beyaert R. Functional diversity and regulation of different interleukin-1 receptor-associated kinase (IRAK) family members. Mol Cell 2003; 11: 293-302.

38 Zhang X, Shan P, Qureshi S, et al. Cutting edge: TLR4 deficiency confers susceptibility to lethal oxidant lung injury. J Immunol 2005; 175: 4834-4838.

39 Qureshi ST, Zhang X, Aberg E, et al. Inducible activation of TLR4 confers resistance to hyperoxia-induced pulmonary apoptosis. J Immunol 2006; 176: 4950-4958.

40 Seibl R, Birchler T, Loeliger S, et al. Expression and regulation of Toll-like receptor 2 in rheumatoid arthritis synovium. Am J Pathol 2003; 162: 1221-1227.

41 Majewska M, Szczepanik M. [The role of Toll-like receptors (TLR) in innate and adaptive immune responses and their function in immune response regulation.] Postepy Hig Med Dosw 2006; 60: 52-63.

42 MacRedmond RE, Greene CM, Dorscheid DR, et al. Epithelial expression of TLR4 is modulated in COPD and by steroids, salmeterol and cigarette smoke. Respir Res 2007; 8: 84.

43 Larsson L, Szponar B, Ridha B, et al. Identification of bacterial and fungal components in tobacco and tobacco smoke. Tob Induc Dis 2008; 4: 4

44 Hemmi $\mathrm{H}$, Takeuchi $\mathrm{O}$, Kawai $\mathrm{T}$, et al. A Toll-like receptor recognizes bacterial DNA. Nature 2000; 408: 740-745.

45 Bauer S, Kirschning CJ, Hacker H, et al. Human TLR9 confers responsiveness to bacterial DNA via species-specific CpG motif recognition. PNAS 2001; 98: 9237-9242.

46 Wagner $H$. Bacterial CpG DNA activates immune cells to signal infectious danger. Adv Immunol 1999; 73: 329-368.

47 Church DF, Pryor WA. Free-radical chemistry of cigarette smoke and its toxicological implications. Environ Health Perspect 1985; 64: 111-126.

48 Orosz Z, Csiszar A, Labinskyy N, et al. Cigarette smoke-induced proinflammatory alterations in the endothelial phenotype: role of NAD(P)H oxidase activation. Am J Physiol Heart Circ Physiol 2007; 292: H130-H139.

49 Manna SK, Rangasamy T, Wise K, et al. Long term environmental tobacco smoke activates nuclear transcription factor-kappa $\mathrm{B}$, activator protein-1, and stress responsive kinases in mouse brain. Biochem Pharmacol 2006; 71: 1602-1609.

$50 \mathrm{Lu} \mathrm{Y,} \mathrm{Wahl} \mathrm{LM.} \mathrm{Oxidative} \mathrm{stress} \mathrm{augments} \mathrm{the} \mathrm{production} \mathrm{of} \mathrm{matrix}$ metalloproteinase-1, cyclooxygenase-2, and prostaglandin E2 through enhancement of NF-kB activity in lipopolysaccharide-activated human primary monocytes. J Immunol 2005; 15; 175: 5423-5429.

51 Wagner H. Toll meets bacterial CpG-DNA. Immunity 2001; 14: 499-502.

52 Imai Y, Kuba K, Neely GG, et al. Identification of oxidative stress and Toll-like receptor 4 signalling as a key pathway of acute lung injury. Cell 2008; 133: 235-249.

53 Tsung A, Klune JR, Zhang X, et al. HMGB1 release induced by liver ischemia involves Toll-like receptor 4 dependent reactive oxygen species production and calcium-mediated signalling. J Exp Med 2007; 204: 2913-2923.

54 Rahman I, Biswas SK, Kirkham PA. Regulation of inflammation and redox signalling by dietary polyphenols. Biochem Pharmacol 2006; 72: 1439-1452.

55 Silverman ES, Drazen JM. Immunostimulatory DNA for asthma: better than eating dirt. Am J Respir Cell Mol Biol 2003; 28: 645-647.

56 Hancox RJ, Welch D, Poulton R, et al. Cigarette smoking and allergic sensitization: a 32-year population-based cohort study. J Allergy Clin Immunol 2008; 121: 38-42. 